\title{
LAS INVERSIONES DE LA UNIÓN EUROPEA EN AMÉRICA LATINA
}

\author{
Alfonso RODRÍGUEZ SÁNCHEZ DE ALVA*
}

\section{RESUMEN}

Las relaciones de la Unión Europea con América Latina se potenciaron tras el ingreso de España y Portugal (1986) en la entonces CEE y son de naturaleza política, económica y de cooperación al desarrollo. El Mercado Único y el Tratado de la UE aceleraron la inversión extranjera directa tanto en el territorio común como en el resto del mundo, ocupando América Latina un lugar preferente. Desde hace años el principal flujo de inversiones extranjeras a esta región procede de la Unión Europea (con España a la cabeza). Las inversiones en la adquisición de empresas públicas privatizadas han sido la modalidad preferida por las empresas europeas y su estrategia dominante ha sido, de una parte, la búsqueda de materias primas para su transformación y posterior venta y exportación. Las inversiones europeas han contribuido a capitalizar la economía latinoamericana pero no han tenido una influencia notable en la modernización y diversificación de su estructura exportadora. ${ }^{1}$

\section{ABSTRACT}

The relation-ships between the European Union and Latin America were boosted after the entrance of Spain and Portugal (1986) in the, at that time, ECC, and they are of political, economical and of cooperation to the development nature. The Only Market and the Treat of the EU accelerate the direct foreign investment as well in the common territory as in the rest of the world, were Latin America occupies a preference place. For several years the main flux of foreign investments comes from the European Union (with Spain as leader). The investments in the acquisition of public enterprises privatised have been the modality preferred by the European enterprises and their strategy has been, on the one hand, the searching of raw materials

\footnotetext{
* Profesor de Economía Aplicada, Universidad de Sevilla.

1. Alfonso Rodríguez Sánchez de Alva (Universidad de Sevilla). Ponencia presentada en el V Congreso de la Asociación Andaluza de Ciencia Regional, celebrado en la Universidad de Cádiz en marzo de 2003.
} 
in order to transform, sell and export them. The European investments have contributed to capitalise the Latin American economy but the have not had a notable influence in the modernisation and diversification of their export structure.

\section{INTRODUCCIÓN}

Las relaciones de la Unión Europea (UE) con América Latina (AL) son antiguas, plurales e intensas. En 1974 se iniciaron las Conferencias Bianuales del Parlamento Europeo y El Parlatino; en 1976 comenzaron las primeras actividades de cooperación; en 1984 se firmó el primer acuerdo de cooperación con una subregión, el Pacto Andino y desde 1984, fecha de apertura del Diálogo de S. José con los países de América Central, se suceden los Convenios, Declaraciones, Firmas de Protocolo o Acuerdos de diversa naturaleza. Las relaciones UE/AL se han basado en un enfoque diferenciado por subregiones (América Latina, Comunidad Andina, MERCOSUR, CARICOM) y por países (México, Chile, Cuba,...).

Tres son los ámbitos históricos de las relaciones UE/AL: político, económico y de cooperación al desarrollo. El Diálogo Político se inició, como ya se ha dicho, con la celebración de la Primera Conferencia Interparlamentaria celebrada en Bogotá en junio de 1974 y desde entonces se han celebrado XVII conferencias de esta naturaleza. Las Cumbres de Río de Janeiro, julio 1999, con asistencia de 48 Jefes de Estado y de Gobiernos de la Unión Europea, América Latina y el Caribe y la de Madrid de mayo de 2002 son seguramente las reuniones de mayor contenido político celebradas entre ambas regiones.

El Diálogo Económico incluye acuerdos con países, subregiones, relaciones comerciales y sistema de preferencias generalizadas (SPG). Con México se han firmado diversos acuerdos pero el más reciente y el de mayor alcance ha sido el Tratado de Libre Comercio que entró en vigor el año 2000 y prevé que en enero de 2003 la Unión Europea haya liberalizado totalmente los aranceles de productos industriales; por parte mejicana el desarme será más lento pero progresivo. El Tratado incluye también la liberalización del sector agrícola. Con Chile la Unión Europea firmó en mayo de 2002 un Acuerdo de Asociación Comercial, Diálogo Político y Cooperación que incluye un Tratado de Libre Comercio que liberara más de un $90 \%$ de los intercambios en un plazo de 10 años. Las relaciones económicas con MERCOSUR, Comunidad Andina y América Central son antiguas e importantes pero carecen de Tratado de Libre Comercio. El comercio internacional UE/AL se ha duplicado entre 1990/00; en este año las exportaciones de la Unión América Latina se cifraron en 54.000 millones de y las importaciones en 48.800 millones de. Desde hace ya varios años la balanza comercial arroja superávit para la Unión Europea. Como después se verá con más detalle la Unión Europea es el primer inversor extranjero en América Latina. 
Numerosos países de el Caribe y América Latina se benefician del SPG que concede un trato comercial favorable para determinados productos agrícolas e industriales.

La Política de Cooperación al Desarrollo Unión Económica/América Latina se ha articulada a través de dos ejes prioritarios: Ayuda Financiera, Técnica y Humanitaria destinada a países pobres y la Cooperación Económica destinada a países de mayores ingresos. Los flujos de financiación de estos programas se han canalizado a través del Banco Europeo de Inversiones (BEI) y de las acciones horizontales AL-INVEST (América Latina Inversiones), ALFA (América Latina Formación Académica), ALURE (programa energético) y AL-URBAN (América Latina Urbanismo). Los países miembros de la Unión Económica y la Comisión Europea son los principales donantes de ayuda oficial al desarrollo a América Latina; los porcentajes de los últimos años siempre han superado el 50\% de la aportación total recibida por América Latina.

\section{INVERSIÓN EXTRANJERA DIRECTA EN EL MUNDO}

En el bienio 1999/00 la inversión extranjera directa (IED) en el mundo alcanzó un máximo histórico ya que el promedio - 1.173 millones de \$-rebasó ampliamente a las realizadas en etapas anteriores; en 2001 la IED mundial solo fue un $64.79 \%$ de la del bienio citado. Esta importante reducción se explica por su descenso en los países desarrollados ya que en los países y economías en desarrollo se mantuvieron en términos generales, aumentaron -caso de China (desde 1996 recibe inversiones anuales superiores a los 40 mil millones de \$)- o descendieron -caso de América Latina y el Caribe (un 10\% en el bienio 2000/01)-

CUADRO 1.

DISTRIBUCIÓN REGIONAL DE LAS ENTRADAS NETAS DE IED Miles de millones de $\$$

\begin{tabular}{|l|r|r|r|r|}
\cline { 2 - 5 } \multicolumn{1}{c|}{} & $1989 / 94^{*}$ & 1996 & 2000 & 2001 \\
\hline Total mundial & 200 & 385 & 1271 & 760 \\
\hline Unión Europea & 77 & 110 & 617 & 199 \\
\hline Estados Unidos & 43 & 84 & 281 & 144 \\
\hline Japón & 1 & 0 & 8 & 4 \\
\hline América Latina y el Caribe & 16 & 52 & 88 & 80 \\
\hline Asia Pacifico & 38 & 96 & 143 & 125 \\
\hline China & 14 & 40 & 41 & 47 \\
\hline
\end{tabular}

Fuente: CEPAL y Elaboración Propia

* Promedio anual 
El enfriamiento de la economía mundial a partir de 1999 ha ralentizado las fusiones y adquisiciones de los principales sectores de la economía internacional (telecomunicaciones, banca y otros) y frenado la corriente de inversiones hacia y entre las economías de mayor desarrollo; el desplome de las cotizaciones bursátiles de los principales mercados de capitales del mundo justifica también la reducción de los flujos internacionales de inversión. En este contexto Japón, África y China son casos singulares. La modesta entrada de capitales en Japón, en contraste con el tamaño de su economía (su PIB por habitante 38.100 \$ (2000) superó al de EE.UU., 35.000 \$ y al de la Unión Europea 21.100 \$) o de sus exportaciones (7.6\% del mundo (2000) frente al $12.4 \%$ de EE.UU. y $45.3 \%$ de la Unión Europea), refleja su conocida escasa apertura a las inversiones extranjeras. África continúa siendo una región olvidada para los inversores extranjeros al contrario que China que a partir de 1995 recibe un creciente y elevado flujo de inversión extranjera directa y como mantiene también un creciente comercio exterior, su nivel de apertura económica internacional es cada vez mayor (inversión extranjera y comercio exterior representan aproximadamente el $45 \%$ de su PIB). Sin duda su reciente ingreso en la OMC ha acelerado estos cambios estructurales.

La Unión Europea es la región que más inversiones reciben del resto del mundo $-48.6 \%$ en el año 2000- y la que más invierte en el resto del mundo -67.2\%-y en América Latina y el Caribe como se verá más adelante.

\section{INVERSIÓNEXTRANJERA DIRECTAEN AMÉRICA LATINA Y ELCARIBE}

El cuadro adjunto pone de relieve la creciente preferencia de la inversión extranjera por América Latina y el Caribe a partir de 1995. En 1990 las entradas se cifraron en 9 mil millones de $\$$, a mitad de la década en 32 mil millones de $\$$, alcanzando el máximo en 1999 con 105 mil millones de \$ y 88 mil millones de \$ en el año 2001.El porcentaje-6.8\%-de inversiones mundiales en América Latina y el Caribe, año 2000, supera al de otros indicadores como por ejemplo al de exportaciones mundiales $-5.6 \%$ - o al de importaciones - $6.0 \%$-. Según lo dicho puede considerarse a América Latina y el Caribe, al menos durante el último quinquenio, como una región objetivo para las inversiones de las empresas multinacionales del mundo y desde luego para las europeas.

Por países, Brasil, México, Argentina y a más distancia Chile, Venezuela, Colombia y Perú son los principales países receptores de inversión extranjera directa. En Centroamérica y el Caribe se concentra un promedio del 6\% de las que recibe América del Sur. Por sectores la inversión extranjera directa se agrupa claramente en el sector terciario con porcentajes que van del 50\% en 1996 al 64\% en el 2000. La adquisición de bancos y grupos financieros (las más recientes en México) por corporaciones 
americanas-CITIGRUP-y españolas-BBVA y BSCH-justifican esta concentración. El sector manufacturero recibió el 24\% de las inversiones en el bienio 1999/2000, porcentaje inferior al del año 1996 -34\%-. La IED en el sector primario se sitúa en torno al $17 \%$ del total como promedio mundial.

\section{CUADRO 2. \\ América Latina y el Caribe: Entradas Netas de IED Millones de \$}

\begin{tabular}{|l|c|r|r|r|}
\cline { 2 - 5 } \multicolumn{1}{c|}{} & $1995 / 1999 *$ & 1995 & 2000 & \multicolumn{1}{c|}{2001} \\
\hline ALADI & 56.150 & 28.084 & 70.643 & 63.705 \\
\hline Brasil & 19.240 & 4.859 & 32.769 & 22.636 \\
\hline México & 10.954 & 9.526 & 13.286 & 24.730 \\
\hline Centroamérica/Caribe & 4.000 & 2.001 & 3.885 & 4.008 \\
\hline Centros Financieros & 9.393 & 1.270 & 13.941 & 11.995 \\
\hline Total & 69.544 & 31.355 & 88.469 & 79.708 \\
\hline
\end{tabular}

Fuente: CEPAL y Elaboración Propia

* Promedio anual

Las importantes reformas económicas (reforma fiscal y disciplina presupuestaria, estabilidad macroeconómica, apertura internacional al comercio y a los capitales, reducción del tamaño del estado, privatizaciones, liberalización financiera, vinculación monetaria con el dólar, en resumen aceptación del programa económico del Consenso de Washington) de comienzo de los noventa propiciaron la entrada de capital extranjero en América Latina y el Caribe en cuantías crecientes según avanzaba la década. La inversión extranjera directa en empresas privatizadas y en fusiones y adquisiciones de empresas privadas, han superado regularmente a las inversiones nuevas. Las privatizaciones han atraído capital extranjero a empresas estatales de energía, petróleo, gas, servicios básicos, telecomunicaciones y transportes y la toma de participación $\mathrm{y}$ adquisiciones de empresas privadas nacionales, regionales y locales se han concentrado en los sectores bancarios, comercio, alimentación, químico, automotriz y recursos naturales. Una vez finalizado el periodo de reformas de la década de los noventa (privatizaciones principalmente) la inversión extranjera directa ha dado preferencia a la consolidación de las compañías adquiridas, antes que a nuevas inversiones.

La reducción de la inversión extranjera directa en América Latina y el Caribe en los últimos años ${ }^{2}$ se explica tanto por razones coyunturales (recesión de los países

2. Con posterioridad a la presentación de este artículo en el V Congreso de la AACR celebrado en la Universidad de Cádiz en marzo de 2003, la CEPAL ha publicado "La Inversión Extranjera en América Latina y el Caribe, 2002" que recoge la tendencia descendente de la IED en ALC por tercer año consecutivo - un 33\% de disminución en 2002 
desarrollados inversores, caída/descenso de las cotizaciones bursátiles de las empresas multinacionales -muchas pagaron un sobreprecio desproporcionado por la obtención de licencias de telefonía móvil-inestabilidad política y económica -Argentina, Colombia, Venezuela-...) como estructurales (conclusión de las principales privatizaciones, reducción de las concesiones de servicios públicos básicos, finalización de alianzas estratégicas con empresas nacionales, regionales o locales).

La inversión extranjera directa nueva en América Latina y el Caribe es escasa salvo en México y Brasil y continúa concentrándose en electricidad (44\% de los proyectos anunciados), telecomunicaciones, petróleo y gas e infraestructura del transporte manteniéndose al margen las manufacturas que sólo representan el $4.3 \%$ de los proyectos futuros. Para la CEPAL la reducción de inversiones extranjeras nuevas se explica tanto por razones externas (la feroz competencia de otras regiones como Asia/Pacífico tras la crisis de 1977/78; la atractiva política China para captar capitales extranjeros ante su esperado ingreso en la Organización Mundial de Comercio en 2001 o por la caída de las inversiones en el mundo -40\% entre 2001/2000-), como internas: América del Sur sobre todo, con la excepción de Chile, ha carecido de una verdadera política para atraer capitales foráneos, limitándose a garantizar y proteger mediante una legislación favorable su entrada; también ha carecido de una estrategia diferenciada que vinculase a las empresas multinacionales a proyectos atractivos nacionales o subregionales.

\section{INTEGRACIÓN EUROPEA E INVERSIÓN EXTRANJERA}

El proceso de construcción europea se activó a partir de 1987 con la aprobación del Acta Única Europea cuyo principal objetivo era la creación de un espacio económico-Mercado Único en el que había que eliminar las barreras técnicas, físicas, fiscales y fronterizas y posibilitar la libre circulación de personas, mercancías, capitales y servicios; es decir alcanzar una plena Unión Económica lo que suponía además ampliar el ámbito de las políticas económicas comunes, reforzar la política de desarrollo regional y cohesión, las políticas de competencia y ampliar el presupuesto comunitario. En 1989A partir de 1999 se inició un largo proceso en varias etapas para la creación de la Unión Monetaria que culminaría el uno de enero de 2002 con la puesta en circulación del euro, la moneda común, en paralelo con las monedas nacionales y la posterior retirada de éstas antes del uno de abril del mismo año.

con respecto a 2001-. También bajó la IED mundial por "la abrupta caída de los precios de las acciones de muchas empresas transnacionales, la marcada reducción de las privatizaciones y la adquisición de los activos internacionales". En el ámbito regional las causas del descenso son la inestabilidad política, el bajo crecimiento económico y el agotamiento del proceso de privatizaciones; el bajo crecimiento de la demanda de EE.UU. tuvo efectos negativos en la inversión en México, Centroamérica y el Caribe. 
El complejo, profundo y completo proceso de integración económica y monetaria de la Unión Europea han tenido importantes incidencias en las inversiones extranjeras directas en esta región y en las inversiones directas de la Unión Europea en el exterior. La teoría económica (teoría de las uniones aduaneras) y la propia evidencia empírica interna, han puesto de manifiesto un efecto expansivo de las inversiones como impacto directo de la integración económica y monetaria. Tanto la mejora de la eficiencia interna de las empresas, como el aumento de la competencia derivada de la ampliación del tamaño de mercados, son aspectos explicativos de la expansión de las inversiones intracomunitaria y extracomunitaria. En efecto, la reestructuración de las actividades productivas que han redimensionado su tamaño para adaptarse al mercado ampliado (aparición de las economías de escala), ha provocado una aceleración de las inversiones en nuevas plantas, en tecnología y en capital humano activándose las fusiones, adquisiciones y alianzas según veremos más adelante. Se ha producido, por lo tanto, un proceso de creación de inversiones (incremento de las inversiones intracomunitaria) y de desviación de inversiones (aceleración de las inversiones comunitaria en el resto de mundo en busca de nuevos mercados y rentabilidades) y de recepción de inversiones del resto del mundo.

El efecto creación de inversiones o de incremento de las inversiones intracomunitaria, como consecuencia de la integración, se explica desde la perspectiva neoclásica porque la eliminación de barreras y la libre circulación de factores (en el caso europeo también por la integración monetaria), facilita los movimientos internacionales de capital posibilitando que éstos se desplacen de regiones y países ricos a la periferia en donde al menos teóricamente la productividad marginal del capital es mayor que en el origen. La aceptación del modelo neoclásico explicaría también el crecimiento económico de las regiones y países de menor desarrollo de la Unión Europea-convergencia real-como resultado de la expansión de las inversiones y de los incrementos de las productividades de los factores.

La integración económica y monetaria tiene reflejos también en la inversión extranjera destinada a la Unión Europea y en la de inversión extranjera de la Unión Europea en el resto del mundo. La preferencia de los inversores internacionales por el mercado comunitario forma parte de la estrategia de las empresas multinacionales extranjeras que desean aprovechar la oportunidad de reforzar su presencia en el mercado interior ampliado libre de obstáculos y barreras, con circulación monetaria unificada (que imposibilita el recurso a la devaluación de la divisa nacional) y una autoridad monetaria autónoma e independiente de los gobiernos nacionales y de las restantes instituciones comunitarias.

El incremento de la inversión directa de la Unión Europea en el resto del mundo podría explicarse tanto por razones internas -aumenta la competencia, reducción de las oportunidades en actividades y proyectos rentables-como externas, un sistema económica internacional más liberalizado y abierto, nuevas normas y reglamentos sobre 
inversiones extranjeras de la Organización Mundial del Comercio (OMC) y en el caso de América Latina y el Caribe, un proceso de reformas económicas iniciado en 1990 que atrajo la atención inversora de las empresas multinacionales de la Unión Europea hacia esta región (efecto desviación de inversiones) ante las expectativas de privatización de empresas públicas, liberalización e integración económica.

El cuadro adjunto no ofrece duda de que la Unión Europea es el bloque económico más activo del mundo como emisor de inversiones en el exterior (67.2\% fue el porcentaje del total en el año 2000) y como receptor de las mismas (48.6\% del total mundial el mismo año). El despegue de la Unión Europea con respecto a EE.UU. y Japón se inició en realidad en la década de los ochenta, se activó a partir de 1987 con la creación del Mercado Único y se disparó a partir de 1996/97, en el último tramo de la integración monetaria.

\section{CUADRO 3.}

INVERSIONES EN LA UE, EE.UU., JAPÓN Y AL.1990, 1995 Y 2000

Millones de \$

\begin{tabular}{|l|c|c|c|c|c|c|c|c|c|c|c|c|}
\cline { 2 - 11 } \multicolumn{1}{c|}{} & \multicolumn{3}{c|}{ UE } & \multicolumn{3}{c|}{ EE.UU. } & \multicolumn{3}{c|}{ Japón } & \multicolumn{3}{c|}{ América Latina } \\
\cline { 2 - 11 } & 1990 & 1995 & 2000 & 1990 & 1995 & 2000 & 1990 & 1995 & 2000 & 1990 & 1995 & 2000 \\
\hline $\begin{array}{l}\text { Inversiones } \\
\text { Directas en } \\
\text { el Exterior }\end{array}$ & 131 & 162 & 960 & 37 & 99 & 139 & 50 & 23 & 33 & 5 & 7 & 13 \\
\hline $\begin{array}{l}\text { Inversiones } \\
\text { Extranjeras } \\
\text { Directas }\end{array}$ & 90 & 117 & 796 & 48 & 58 & 295 & 2 & 1 & 8 & 9 & 32 & 86 \\
\hline $\begin{array}{l}\text { Salidas de } \\
\text { Inversiones } \\
\text { Directas } \\
\text { como porcen- } \\
\text { tajes del total } \\
\text { Mundial }\end{array}$ & 53.9 & 45.3 & 67.2 & 15.2 & 27.8 & 12.0 & 20.5 & 6.4 & 2.9 & 2.0 & 1.9 & 1.2 \\
\hline $\begin{array}{l}\text { Entradas de } \\
\text { inversiones } \\
\text { como porcen- } \\
\text { tajes del total } \\
\text { Mundial }\end{array}$ & 45.4 & 34.7 & 48.6 & 22.7 & 17.5 & 23.2 & 0.0 & 0.0 & 0.6 & 4.2 & 9.6 & 6.8 \\
\hline
\end{tabular}

Fuente: CEPAL y Elaboración Propia 
Es evidente que le inversión extranjera directa ha sido un instrumento fundamental de la inserción internacional de la Unión Europea tanto en su versión intracomunitaria como en la extracomunitaria, especialmente desde 1998/99 en que los flujos de inversión se dispararon alcanzando el año 2000 los 960 mil millones de \$ (131 mil millones en 1990 y 162 mil millones en 1995).

El cuadro adjunto refleja los flujos de salida de la inversión directa de la Unión Europea hacia sí misma (inversión intracomunitaria) y hacia el resto del mundo. Desde 1992 hasta 1996 los flujos intracomunitarios superaron a los extracomunitarios, lo que evidencia que el proceso de integración interno-UEM-tuvo el efecto de creación de inversiones antes expuesto. Únicamente en el bienio 1997/98 las inversiones fuera de la UE superaron a las realizadas en el interior (desviación de inversiones); en el bienio 1999/00 vuelven a destacar las inversiones en el interior de la UE (ver cuadro adjunto). Tanto en la UE como en el resto de mundo las fusiones y adquisiciones de empresas representan porcentajes muy elevados del total de las inversiones extranjeras. Según la UNCTAD las fusiones y adquisiciones suponían un $60 \%$ de las inversiones totales mundiales y en el caso de la Unión Europea el porcentaje fue del 70\% -promedio 1993/98-.

\section{CUADRO 4. \\ UNión EuRopea: FLUJOS DE SALIDA DE LA IED Millones de \$ y porcentajes}

\begin{tabular}{|l|r|r|r|r|}
\cline { 2 - 5 } \multicolumn{1}{c|}{} & 1992 & 1996 & 1999 & 2000 \\
\hline Unión Europea & 63.792 & 78.202 & 316.716 & 427.114 \\
\hline Fuera de la Unión Europea & 23.076 & 59.272 & 276.578 & 280.770 \\
\hline \multicolumn{1}{c|}{ - Norteamérica } & 9.368 & 21.435 & 192.078 & 166.375 \\
\hline \multicolumn{1}{c|}{ - Japón } & 748 & 3.428 & 8.826 & 4.215 \\
\hline \multicolumn{1}{c|}{ América Latina } & 1.477 & 10.675 & 35.128 & 35.220 \\
\hline $\begin{array}{l}\text { Participación de AL en los flujos } \\
\text { europeos fuera de la UE \% }\end{array}$ & 6,4 & 18,0 & 12,7 & 12,5 \\
\hline
\end{tabular}

Fuente: CEPAL y Elaboración Propia

El gráfico adjunto indica que las inversiones de la Unión Europea entre 1992/2000 se concentraron principalmente en la propia región 54\%, en América del Norte 27\% y en América Latina un 6\%. 


\section{UNIÓN EUROPEA: DISTRIBUCIÓN REGIONAL DE LAS INVERSIONES \\ EN EL EXTERIOR, 1992-2000 \\ (En porcentaje)}

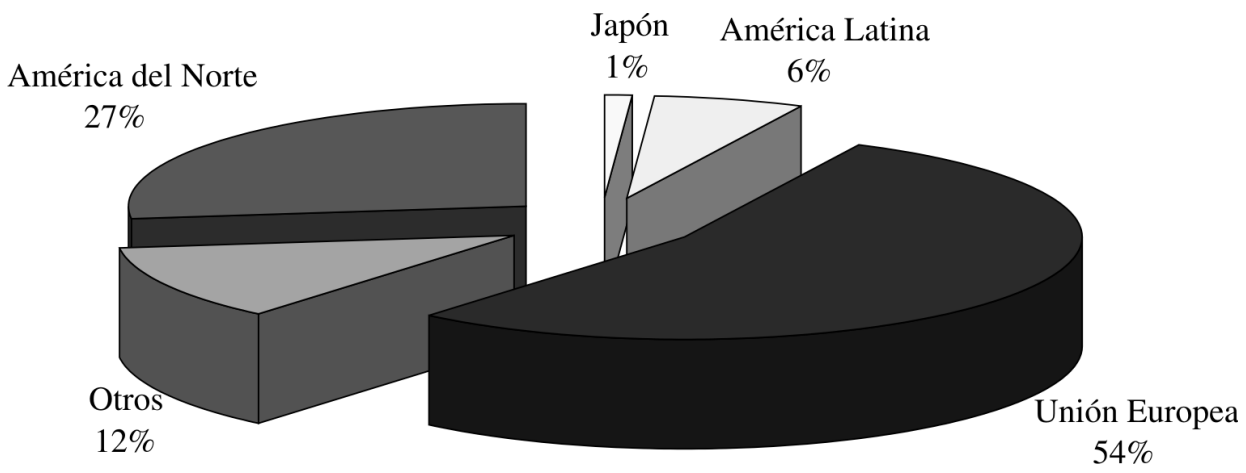

Fuente: CEPAL, Unidad de Inversiones y Estrategias Empresariales de la División de Desarrollo Productivo y Empresarial, sobre la base de la Oficina de Estadística de las Comunidades Europeas (EUROSTAT), European Union Foreign Direct Investment Yearbook, 2000, Luxemburgo, 2000

El cuadro y el gráfico confirma que América Latina es desde 1994 una región prioritaria de las inversiones de las empresas multinacionales europeas con cifras que superaron los 35 mil millones de \$ en 1999/00; desde 1997 las inversiones de la Unión Europea superaron y se despegaron ampliamente de las de EE.UU. según veremos enseguida.

\section{INVERSIONES DE LA UNIÓN EUROPEA EN AMÉRICA LATINA}

\subsection{Importe y destinos}

El principal flujo de inversiones hacia América Latina procede de la Unión Europea -35.000 mil millones de \$ aproximadamente fue el promedio del bienio 1999/00-; Estados Unidos con 20.000 mil millones de \$ fue el segundo inversor y el tercero Japón con un promedio de 5.000 mil millones de \$. A partir de 1998 se incrementaron los flujos de inversiones europeas hacia América Latina según se observa en el cuadro adjunto. En cifras absolutas las inversiones pasaron de 1.638 millones de $\$$-promedio de 1992/93- a más de 35.174 millones de $\$$ al final de la década, lo que convirtió a América Latina en la principal destinataria de las inversiones europea en regiones de menor desarrollo. 
CUADRO 5.

UNIÓN EUROPEA: INVERSIONES DIRECTAS EN AMÉRICA LATINA, POR PAÍS Y SUBREGIÓN DE DESTINO, 1992-2000

\begin{tabular}{|l|r|r|r|r|r|r|r|r|r|}
\hline & 1992 & 1993 & 1994 & 1995 & 1996 & 1997 & 1998 & 1999 & 2000 \\
\hline América del Sur & 1.893 & 1.340 & 4.296 & 3.986 & 8.587 & 15.390 & 25.835 & 32.870 & 31.563 \\
\hline Mercosur & 1.147 & 1.105 & 2.172 & 2.267 & 6.217 & 8.238 & 24.033 & 29.455 & 23.176 \\
\hline Argentina & 531 & 598 & 974 & 1.129 & 1.803 & 2.541 & 3.757 & 17.801 & 4.611 \\
\hline Brasil & 612 & 495 & 1.171 & 1.112 & 4.336 & 5.633 & 20.143 & 11.491 & 18.397 \\
\hline Comunidad Andina & 693 & 47 & 2.382 & 1.200 & 1.827 & 5.051 & 23 & 1.230 & 7.598 \\
\hline Colombia & 85 & -163 & 259 & 426 & 675 & 2.171 & 1.121 & 373 & 2.091 \\
\hline Venezuela & 179 & 102 & 68 & 296 & 507 & 2.254 & -1.509 & 518 & 4.095 \\
\hline Otros países andinos & 429 & 108 & 2.055 & 475 & 645 & 626 & 411 & 339 & 1.412 \\
\hline Chile & 53 & 188 & 372 & 522 & 543 & 2.102 & 1.778 & 4.337 & 790 \\
\hline México & 6.361 & 92 & 70 & 1.462 & 945 & 3.430 & 1.572 & 1.602 & 2.408 \\
\hline América Central & 388 & 367 & 1.030 & -796 & 1.143 & 979 & 1.638 & 656 & 1.249 \\
\hline Total América Latina & 1.477 & 1.799 & 6.026 & 4.652 & 10.675 & 19.799 & 29.045 & 35.128 & 35.220 \\
\hline
\end{tabular}

Fuente: CEPAL, Unidad de Inversiones y Estrategias Empresariales sobre información de EUROSTAT.

En el cuadro adjunto se observa que MERCOSUR concentró en el año 2000 el $65 \%$ de las inversiones totales y la Comunidad Andina el 21.5\%. Por países aparecen muy destacado Brasil, seguido de Argentina, Chile y México. Entre 1992 y 2000 MERCOSUR recibió el 68\% de los flujos de inversión de la Unión Europea.

Las inversiones en la adquisición de empresas públicas privatizadas y en su posterior capitalización, renovación y modernización de su tejido empresarial absorbieron una parte considerable de las inversiones europeas en Argentina, Perú, Venezuela, Colombia, Bolivia y otros países; fue el capítulo más activo de la inversión extranjera directa de la Unión Europea en América Latina. En Chile -el tamaño del sector público es menor que en otros países de la región- la inversión europea se concentró en la compra de empresas privadas - energía, telecomunicaciones, bancosy en México en la adquisición de actividades manufactureras para la exportación (automóviles principalmente) al mercado de los EE.UU. En América Central la presencia inversora europea fue modesta por tratarse de un mercado muy vinculado a intereses norteamericanos. 


\section{CUADRO 6. \\ INVERSIONES ESPAÑOLAS EN AMÉRICA LATINA. 1997-2000. Millones de \$}

\begin{tabular}{|l|r|}
\hline Telefónica de España & 30.449 \\
\hline Banco Santander Central Hispano & 12.639 \\
\hline Banco Bilbao Vizcaya Argentaria & 7.848 \\
\hline Repsol YPF & 17.253 \\
\hline Endesa España & 7.226 \\
\hline Iberdrola & 1.806 \\
\hline Unión FENOSA & 840 \\
\hline \multicolumn{2}{|c|}{ TOTAL } \\
\hline
\end{tabular}

El cuadro adjunto refleja la alta concentración empresarial de los inversionistas españoles en América Latina: una empresa de telecomunicaciones, Telefónica, invirtió entre 1997/2000 el 40\% de la inversión española total; las inversiones de dos empresas financieras -BBVA y BSCH-superaron las del Reino Unido e Italia y las tres compañías citadas más Repsol/YPF (petróleo y derivados) con inversiones conjuntas de 68.189 millones dólares superaron ampliamente las del conjunto de países de la Unión Europea sin el Reino Unido.

\subsection{Estrategias empresariales de las inversiones de la Unión Europea en América Latina}

Para interpretar y comprender mejor la estructura y patrones de las inversiones recibidas en la región en los últimos años, es necesario diferenciar claramente el modelo económico vigente en América Latina hasta aproximadamente 1989/90, del nuevo modelo implantado por el FMI/BM basado en el Consenso de Washington ya citado. Hasta 1989/90 en la región regia un modelo de economía cerrada basado en la estrategia de industrialización por sustitución de importaciones (ISI) que mediante elevados aranceles y otros instrumentos protectores reservaba el mercado interior para las empresas nacionales limitando así la competencia y la presencia de empresas internacionales. El fracaso de este modelo llevó a la región a una situación de inestabilidad interna y externa y a la acumulación de deuda internacional, la mayor parte de la cual estaba nominada en $\$$ y a tipo de interés variable, todo lo cual exigía una profunda reestructuración macro y microeconómica y el concurso y la participación de las principales instituciones financieras multilaterales. El modelo económico vigente desde 1990/91 (de desarrollo desde dentro o de regionalismo abierto con equidad en terminología de la CEPAL) da preferencia a la apertura económica 
internacional, a la liberalización interna, a la privatización de empresas estatales, a la estabilización económica y las reformas de los mercados.

La CEPAL viene adoptando desde hace ya vario años una clasificación propuesta por Behrman (1972) y difundida posteriormente por Dunming que recoge en un cuadro de doble entrada, de una parte, la estrategia corporativa de las inversiones de las empresas trasnacionales en América Latina, y de otra, los sectores y actividades destinatarias de las mismas. La estrategia propuesta se clasifica en cuatro apartados: 1) Búsqueda de eficiencia; 2) Búsqueda de recursos naturales y materias primas; 3) Búsqueda de acceso a los mercados locales, nacionales y subregionales (MERCOSUR, CAN, CARICOM...) y 4) Búsqueda de capacidades estratégicas (en investigación y desarrollo por ejemplo).

\section{CUADRO 7. \\ ESTRATEGIAS EMPRESARIALES}

\begin{tabular}{|l|l|l|l|l|}
\hline Sector & $\begin{array}{r}\text { Estrategia Em- } \\
\text { presarial } \\
\text { de Eficiencia }\end{array}$ & $\begin{array}{c}\text { Búsqueda de } \\
\text { Mat. Primas }\end{array}$ & $\begin{array}{c}\text { Búsqueda de } \\
\text { Acceso Merc. }\end{array}$ & $\begin{array}{c}\text { Búsqueda de } \\
\text { capacidad / } \\
\text { estrat. }\end{array}$ \\
\hline Automóviles & México (TLC) & & Mercosur & \\
\hline Electrónica & México/Caribe (TLC) & & & \\
\hline Confecciones & México/Caribe (TLC) & & América Latina & \\
\hline $\begin{array}{l}\text { Alimentos } \\
\text { Bebidas }\end{array}$ & & $\begin{array}{c}\text { Ventas y y } \\
\text { Exportación }\end{array}$ & América Latina & \\
\hline Química & & & América Latina & \\
\hline Cemento & & & Argentina, Chile & \\
\hline $\begin{array}{l}\text { Telecomunic./ } \\
\text { Electricidad }\end{array}$ & & Exportación & $\begin{array}{c}\text { Brasil, Colombia, } \\
\text { Perú, América Latina }\end{array}$ & \\
\hline $\begin{array}{l}\text { Petróleos y } \\
\text { Derivados }\end{array}$ & & $\begin{array}{c}\text { Argentina, México, } \\
\text { Chile, Brasil, AL }\end{array}$ & \\
\hline Banca & & América Latina & \\
\hline Comercio minorista & & & & \\
\hline
\end{tabular}

Fuente: CEPAL y Elaboración Propia

AuTOMóviLES. Durante la década de los cincuenta y sesenta varias empresas europeas (Volkswagen, Renault, Fiat y otras) localizaron plantas productivas en Brasil, México y Argentina aprovechando las ventajas e incentivos de mercados nacionales protegidos por los gobiernos para atraer la industria del automóvil considerada 
como uno de los pilares de la industrialización por sustitución de importaciones. La debilidad de los mercados interiores, reflejo de la larga y profunda crisis de la década de los 80, enfrió la modernización del sector y algunas empresas redujeron notablemente su actividad inversora o dejaron el control de sus filiales a empresas locales. La apertura económica de los 90, la activación de los esquemas subregionales de integración -principalmente el MERCOSUR- y el mayor protagonismo del mercado, devolvió la confianza a las empresas multinacionales europeas que contaban con presencia en Brasil y Argentina o que querían posesionarse ventajosamente en el mercado estadounidense instalándose o potenciando su presencia en México país que abrió las puertas al mercado del norte a partir de 1994 con la entrada en vigor del Tratado de Libre Comercio de América del Norte. Un ejemplo de esta estrategia la ofrece la empresa alemana Volkswagen que en 1990 vendía 130.000 coches en México y 50.000 se exportaban y en el año 2000 las ventas en México se redujeron a 60.000 y las exportaciones se situaron en 350.000 unidades. En este año la participación de América de América Latina en las ventas totales de Volkswagen fue del $17.2 \%$, del $13.9 \%$ las de Fiat, 9.2\% las de Daimler Chrysler y 8.4\% las de Renault.

ALIMENTOS Y BEBIDAS. La estrategia de las principales empresas europeas (Nestlé, Danone, Parmalat, Unilever..) en América Latina ha sido la de la búsqueda de mercados nacionales, locales o subrregionales o la de materias primas tan abundante en la región para procesarla y venderla o exportarla como producto industrial. La empresa multinacional italiana Parmalat facturó en América Latina en el año 2000 el 27\% de sus ventas totales. Esta región representó el $11.5 \%$ y el $10.6 \%$ de las ventas totales de Danone y Unilever respectivamente.

QuímICA. La búsqueda de mercados nacionales ha sido la principal razón de la localización de empresas químicas europeas en América Latina desde finales del siglo XIX. Como las restantes empresas multinacionales europeas, las químicas han transitado desde la larga etapa de sustitución de importaciones hasta la más reciente de apertura, integración económica y globalización. Tradicionalmente han mantenido un bajo perfil exportador. Las fusiones y alianzas de las empresas químicas europeas con compañías locales han servido para afianzar y ampliar su presencia en países y subregiones ampliando por lo general la gama de productos destinada al mercado. Unilever coloca en América Latina el 12\% de sus ventas totales; Bayer el $7.9 \%$ y Rhone-Poulenc el 7.7\%. Para todas estas empresas Brasil es su principal mercado seguido de México y Argentina.

TELECOMUNICACIONES Y ENERGÍA ELÉCTRICA. Con la entrada en vigor del Acta Única Europea (1987) se inició una lenta pero inexorable liberalización de los sectores de las telecomunicaciones, electricidad y otros; las empresas, generalmente de gran tamaño o monopolios naturales, ante el desafío de la competencia y la ampliación 
del mercado interior, reaccionaron mediante una estrategia de fusiones, adquisiciones y alianzas que redimensionaron sus escalas productivas capacitándolas para nuevas aventuras empresariales; estas circunstancias y las atractivas expectativas para las inversiones internacionales de las reformas, apertura, liberalización y privatización de empresas de telecomunicaciones, energéticas y eléctricas, aceleraron el flujo de inversiones europeas hacia Latinoamérica a partir de la segunda mitad de la década de los 90. Según la CEPAL las inversiones europeas se concentraron fuertemente en "sectores y países tanto desde la perspectiva del origen como del destino". La CEPAL también destaca la preferencia de las inversiones europeas por adquirir paquetes de acciones de empresas públicas privatizadas o privadas de servicios públicos en lugar de inversiones en proyectos nuevos. Tanto en telecomunicaciones como en el sector eléctrico las empresas españolas se situaron a la cabeza de las inversiones europeas. En el año 2000 la participación de América Latina en las ventas totales de Telefónica España fue del 56.7\%; del 37.3\% las de Endesa-España; 23.3\% las de Iberdrola y 13.9\% las de Repsol/YPF, Olivetti (Italia), Portugal Telecomunicaciones y Electricidade y Electricite de France cuentan también con presencia en diversos países de América Latina.

PETRÓleOS y DeRIVADOS. En ALC las principales empresas productoras de petróleo PEMEX (México), PDVSA(Venezuela), PETROBRAS (Brasil), son mayoritariamente estatales; las mixtas pero con participación mayoritaria del Estado, ECOPETROL (Colombia) y las privatizadas (Argentina, Bolivia, Perú...) ocupan lugares secundarios. Las principales EMN, EXXON-MOBIl y ROYAL DUTCH SHELL, cuentan con escasa presencia en ALC. De las EMN la de mayor producción de petróleo es la española REPSOL/YPF que ocupa también un lugar destacado (31) en la producción de gas. Otras empresas europeas de gran tamaño (BRITISH PETROLEUM AMOCO, TOTAL FINA ELF..) que ya contaban con actividades en la región, han diversificado su presencia aprovechando las nuevas oportunidades inversoras.

BANCA. La liberalización del sector financiero en la Unión Europea a partir de 1987 y la apertura a las inversiones internacionales en América Latina seguida de una reducción de las barreras de entrada para las actividades financieras y la adopción de normas internacionales de supervisión y control por las autoridades monetarias de los principales países de América Latina, incentivaron los flujos que capital hacia esta región principalmente de la banca española, que mediante una estrategia de adquisición de paquetes mayoritarios de acciones de bancos subregionales y nacionales privados, pasó a controlar el mercado de depósitos y de inversiones de segmentos familiares y empresariales, generalmente marginados por la banca doméstica tradicional cuya clientela principal era el sector público y las grandes empresas extranjeras o nacionales. La banca española introdujo también productos y servicios con escasa 
penetración anterior en América Latina pero muy frecuentes en Europa y progresivamente ha ido aumentando el negocio con las PYMES y con las economías domésticas.

\section{MODALIDADES DELA INVERSIÓNEXTRANJERA DIRECTAEN AMÉRICA LATINA Y EL CARIBE}

Son fundamentalmente tres:

- Inversiones en proyectos nuevos. Actividades inexistentes, construcción de nuevas plantas, incorporación de nuevas tecnologías con resultados de ampliación de la capacidad productiva. Esta modalidad no ha tenido un protagonismo destacado.

- Inversiones en la adquisición de empresas públicas privatizadas o bajo la modalidad de concesiones. Implica fuertes inversiones en la sustitución de viejos y obsoletos bienes de capital por modernos equipos dotados de tecnología competitiva, en formación y capital humano o en la gestión y comercialización de productos. Como ejemplo podrían citarse las telecomunicaciones, producción y distribución de energía eléctrica, gas, algunos servicios públicos, petróleo, construcción, suministro de agua potable y gestión de aeropuertos entre otros. Esta modalidad atrajo fuertes inversiones de empresas multinacionales desde el mismo comienzo de las reformas económicas al inicio de la década de los noventa; ha sido el campo más atractiva para el capital extranjero de manera que la poca actividad inversora desde comienzo del milenio se debe al "agotamiento" de las políticas privatizadoras si bien todavía permanecen en el ámbito estatal (y seguramente por mucho tiempo) el sector de hidrocarburo en Colombia, México y Venezuela, electricidad en México y minería en Chile entre otros.

- Adquisiciones de empresas privadas mediante fusiones, tomas de participaciones, y alianzas. Todos los sectores productivos han estado en el horizonte de los inversionistas extranjeros aunque los preferidos han sido el eléctrico, telecomunicaciones, petróleo y gas, servicios financieros y automóviles. Sin duda las grandes empresas extranjeras tienen un elevado peso en la economía de América Latina y el Caribe:

- De las 200 mayores empresas exportadoras -año 2000- el 49\% son de propiedad extranjera, el $44.5 \%$ privadas y el $6.5 \%$ estatales. Las extranjeras exportaron el $43.7 \%$, las privadas el $27 \%$ y las estatales el $29.3 \%$. Petróleos de Venezuela y Petróleos de México, ambas empresas estatales, ocupan los dos primeros lugares en el ranking de las 20 mayores empresas exportadoras de América Latina. 
- De las 100 principales empresas manufactureras (1998/00) de América Latina, 59 son extranjeras, 40 privadas (48 en 1990/92) y 1 estatal (4 en 1990/92); en ventas las empresas extranjeras alcanzaron en 1998/2000 el $61.37 \%$ de las ventas totales (53.2\% en 1990/92) y las privadas el $37.58 \%$ (antes el 42.6\%).

- De las 100 principales filiales de empresas multinacionales (2000) según volumen de ventas, 49 son de la Unión Europea, una, Nestlé de Suiza y el resto principalmente de EE.UU. y algunas de Japón. Las españolas de mayor venta son: REPSOL/YPF (30); Telefónica de España-Brasil (51); Endesa-España (91); Telefónica-España Argentina (181). Las actividades automotrices (General Motor México y Daimler Chrysler de México), petróleo (REPSOL/YPF), electricidad y telecomunicaciones ocupan los lugares de cabeza.

\section{INFLUENCIA DE LA INVERSIÓN EXTRANJERA DIRECTA EN LA COMPETITIVIDAD DE LA ECONOMÍA LATINOAMERICANA}

Aunque es una tarea dificultosa determinar los impactos de las inversiones extranjeras en la economía latinoamericana, sí en cambio puede a firmarse que hay una correlación entre flujos de inversiones productivas y ganancias en la inserción internacional de la economía regional que puede medirse, por ejemplo, por el aumento de los ingresos por exportaciones o por cambios estructurales en la composición de las mismas (mayor diversificación de productos, exportaciones con mayor valor añadido o mayor contenido tecnológico sin olvidar la nueva demanda de importaciones exigida por los sectores productivos capitalizados o por las exportaciones vinculadas). La inversión extranjera directa tiene, por lo tanto, fuertes vínculos con el comercio internacional, con la estructura productiva interna de oferta, demanda y renta y por lo tanto con el crecimiento económico. Tomando como referencia los dos cuadros finales se va a analizar la competitividad internacional de América del Sur y de México, dos modelos diferentes de inserción externa de la región.

América del Sur ha reducido su participación en el mercado mundial de importaciones al pasar del $3.4 \%$ en 1985 al 2.6\% en el 2000; sólo el capitulo de recursos naturales mejoró su inserción internacional. En la composición de sus exportaciones mantiene un porcentaje mayoritario los recursos naturales $-4.2 \%$ en el año 2000 aunque también se observa una alteración positiva en el porcentaje de exportaciones de manufacturas no basadas en recursos naturales $-19.8 \%$ en 1985 y $26.8 \%$ en $2000-$; no obstante los diez principales grupos exportadores de América del Sur (véase el cuadro) son recursos naturales y productos básicos o manufacturas basadas en recursos naturales; ninguno de los grupos antes mencionados está comprendido entre las 50 agrupaciones más dinámica de las importaciones mundiales de 1985/00. Según lo dicho parece razonable pensar que la inversión extranjera directa en América del 
Sur no han mejorado significativamente su estructura exportadora que continúa siendo tradicional, primaria, basadas en recursos naturales y en sus manufacturas y con escasos vínculos con el entramado productivo; la modesta contribución de la inversión extranjera directa a la mejora de la competitividad internacional de América del Sur podría residir en las estrategias inversoras de las empresas trasnacionales europeas y norteamericanas orientadas, como ya se ha dicho, a la búsqueda de mercados nacionales, locales o subregionales y a la búsqueda de materias primas siendo, por lo tanto, un objetivo residual mejorar la calidad de las exportaciones internacionales.

El patrón de inserción internacional de México, Centroamérica y el Caribe es diferente al de América del Sur al estar fundado en una estrategia inversora orientada a mejorar la producción de manufacturas, piezas y componentes para el mercado internacional del norte. Responde a un modelo de inserción/especialización de exportaciones de manufacturas dirigido al mercado de EE.UU. aprovechando que su apertura se había acelerado tras el Tratado de Libre Comercio de 1994. En 1990 las exportaciones mexicanas a EE.UU. representaban un porcentaje reducido de sus exportaciones totales en tanto que en el año 2000 el porcentaje fue del 89\%. Es evidente que las inversiones de las empresas multinacionales en México (también en América Central y el Caribe) han mejorado la competitividad internacional de estas economías, su potencial exportador (las exportaciones mexicanas representan casi el 50\% de las exportaciones totales de América Latina) y su diversificación. En el cuadro adjunto puede observarse el creciente protagonismo del comercio internacional de México, Centroamérica y el Caribe entre 1985 y 2000 . Ha mejorado:

Su participación porcentual-del $2.4 \%$ al 3.4\%-en las importaciones mundiales y también su estructura exportadoras pues en el año 2000 estaba compuesta mayoritariamente $-72.7 \%$ - por manufacturas no basadas en recursos naturales $(30.5 \%$ en 1985) en las que predominan las exportaciones de productos de contenido tecnológico medio y alto hacia el mercado del norte. Una parte sustancial de la actividad exportadora con EE.UU. se localiza en la frontera mexicana y se vincula al sistema internacional de producción integradas (SIPI) de las empresas trasnacionales de automóvil, electrónica y otras manufacturas. Es esto un ejemplo de inversión extranjera orientada a la búsqueda de una mayor eficiencia productiva mediante de incorporación de sus plantas al SIPI. De acuerdo con lo dicho es evidente que la inversión extranjera directa ha mejorado la competitividad internacional de México y ampliado notablemente su potencial exportador. No obstante este modelo de inserción internacional tiene algunas sombras que no son posibles analizar aquí con detalle; de una parte, es cierto que han aumentado considerablemente las exportaciones pero también las importaciones vinculadas a las exportaciones lo que ha deteriorado la balanza comercial; y de otra, no parecen muy satisfactorios los impactos de la industria manufacturera exportadora con el resto de la economía mexicana cuyo tejido productivo está poco vinculado con las manufacturas fronterizas ofreciendo todo esto como resultado una clara desconexión que resta potencial de crecimiento y de creación de empleo a la economía mexicana. 
CUADRO 8.

AMÉRICA DEL SUR: ASPECTOS DE SU COMPETITIVIDAD INTERNACIONAL EN LAS IMPORTACIONES MUNDIALES, 1985-2000 (En porcentaje)

\begin{tabular}{|c|c|c|c|c|c|}
\hline & & 1985 & 1990 & 1995 & 2000 \\
\hline I. Participación de mercado & & 3,4 & 2,8 & 2,8 & 2,6 \\
\hline Recursos naturales $^{\mathrm{a}}$ & & 6,8 & 7,2 & 8,3 & 8,5 \\
\hline Manufacturas basadas en los recursos naturales ${ }^{\mathrm{b}}$ & & 5,6 & 4,7 & 4,9 & 4,9 \\
\hline Manufacturas no basadas en los recursos naturales ${ }^{\mathrm{c}}$ & & 1,2 & 1,1 & 1,1 & 1,0 \\
\hline - Baja tecnología ${ }^{\mathrm{d}}$ & & 2,0 & 1,8 & 1,7 & 1,4 \\
\hline - Tecnología mediana ${ }^{\mathrm{e}}$ & & 1,2 & 1,2 & 1,3 & 1,3 \\
\hline - Alta tecnología $\mathrm{a}^{\mathrm{f}}$ & & 0,5 & 0,4 & 0,3 & 0,5 \\
\hline Otros $^{\mathrm{g}}$ & & 2,1 & 1,2 & 1,4 & 1,6 \\
\hline II. Estructuras de las exportaciones & & 100,0 & 100,0 & 100,0 & 100,0 \\
\hline Recursos naturales $^{\mathrm{a}}$ & & 48,3 & 44,8 & 44,1 & 44,2 \\
\hline Manufacturas basadas en los recursos naturales ${ }^{\mathrm{b}}$ & & 29,9 & 27,8 & 27,0 & 26,6 \\
\hline Manufacturas no basadas en los recursos naturales ${ }^{\mathrm{c}}$ & & 19,8 & 26,1 & 27,1 & 26,8 \\
\hline - Baja tecnología ${ }^{\mathrm{d}}$ & & 8,2 & 10,5 & 10,0 & 8,4 \\
\hline - Tecnología mediana ${ }^{\mathrm{e}}$ & & 10,0 & 13,6 & 15,1 & 14,3 \\
\hline - Alta tecnología ${ }^{\mathrm{f}}$ & & 1,6 & 2,0 & 2,0 & 4,0 \\
\hline Otros $^{\mathrm{g}}$ & & 1,9 & 1,4 & 1,7 & 2,3 \\
\hline III. 10 exportaciones principales según contribución ${ }^{\mathrm{h}}$ & i & 52,2 & 44,8 & 41,4 & 43,1 \\
\hline 333 Aceites de petróleo crudos, aceites crudos de min. bitumin. & + & 12,4 & 10,0 & 11,2 & 14,5 \\
\hline 334 Productos derivados del petroleo, refinados & - & 10,7 & 7,3 & 4,4 & 5,6 \\
\hline 682 Cobre & + & 3,1 & 4,4 & 3,7 & 3,6 \\
\hline 081 Piensos para animales & + & 4,3 & 4,3 & 4,7 & 3,6 \\
\hline 057 Frutas y nueces (exc. nueces oleaginosas) frescas o secas & + & 2,8 & 3,9 & 3,6 & 3,4 \\
\hline 281 Mineral de hierro y sus concentrados & + & 4,1 & 4,4 & 3,3 & 2,8 \\
\hline 071 Café y sucedáneos del café & - & 9,6 & 4,5 & 4,1 & 2,7 \\
\hline 287 Minerales de metales comunes y sus concentrados & + & 2,1 & 2,4 & 2,4 & 2,6 \\
\hline 222 Sem. y frutas oleaginosas, enteras o partidas, blandas & + & 2,2 & 2,4 & 2,2 & 2,4 \\
\hline 251 Pulpa y desperdicios de papel & + & 0,9 & 1,2 & 1,8 & 1,9 \\
\hline
\end{tabular}

Fuente: Basados en el programa de cómputo TradeCAN 2002 Edition, CEPAL.

Grupos de bienes basados en la clasificación Uniforme de Comercio Internacional (CUCI Rev.2)

a. Contiene 45 productos básicos de sencillo procesamiento, incluye concentrados.

b. Contiene 65 elementos: 35 grupos agropecuarios/forestales y otros 30 (mayormente metales -excepto acero-, productos petroleros, cementos y vidrio, etc.)

c. Contiene 120 grupos que representan la suma de $d+e+f$.

d. Contiene 44 elementos: 20 grupos del clúster de textil y prendas de vestir, más otros 24 (productos de papel, vidrio y acero, joyas).

e. Contiene 58 elementos: 5 grupos de la industria automotriz, 22 de la industria de procesamiento y 31 de la industria de ingeniería.

f. Contiene 18 elementos: 11 grupos del clúster de electrónica, más otros 7 productos (farmacéuticos, turbinas, aviones, instrumentos).

g. Contiene 9 grupos no clasificados (mayormente de la sección 9)

h. Grupos que corresponden (*) a los 50 más dinámicos en las importaciones mundiales, 1985-2000.

i. Grupos donde se gana (+) o se pierde (-) participación de mercado en las importaciones mundiales, $1985-2000$. 


\section{CUADRO 9.}

MéXico, Centroamérica y CUenCa del Caribe: AsPectos de SU Competitividad INTERNACIONAL EN LAS IMPORTACIONES MUNDIALES, 1985-2000 (En porcentaje)

\begin{tabular}{|c|c|c|c|c|c|}
\hline & & 1985 & 1990 & 1995 & 2000 \\
\hline I. Participación de mercado & & 2,4 & 2,0 & 2,4 & 3,4 \\
\hline Recursos naturales $^{\mathrm{a}}$ & & 5,0 & 3,6 & 3,3 & 3,5 \\
\hline Manufacturas basadas en los recursos naturales ${ }^{\mathrm{b}}$ & & 2,1 & 1,8 & 1,9 & 2,1 \\
\hline Manufacturas no basadas en los recursos naturales $^{\mathrm{c}}$ & & 1,3 & 1,6 & 2,3 & 3,6 \\
\hline - Baja tecnología ${ }^{\mathrm{d}}$ & & 1,3 & 1,5 & 2,5 & 3,9 \\
\hline - Tecnología mediana ${ }^{\mathrm{e}}$ & & 1,3 & 1,6 & 2,5 & 3,7 \\
\hline - Alta tecnología ${ }^{\mathrm{f}}$ & & 1,7 & 1,4 & 1,9 & 3,2 \\
\hline Otros $^{\mathrm{g}}$ & & 2,1 & 2,0 & 2,4 & 3,3 \\
\hline II. Estructuras de las exportaciones & & 100,0 & 100,0 & 100,0 & 100,0 \\
\hline Recursos naturales $^{\mathrm{a}}$ & & 50,6 & 31,3 & 20,1 & 14,5 \\
\hline Manufacturas basadas en los recursos naturales $^{\mathrm{b}}$ & & 16,0 & 15,3 & 11,7 & 8,9 \\
\hline Manufacturas no basadas en los recursos naturales ${ }^{c}$ & & 30,5 & 49,8 & 64,7 & 72,7 \\
\hline - Baja tecnología ${ }^{\mathrm{d}}$ & & 7,4 & 12,9 & 17,2 & 18,3 \\
\hline - Tecnología mediana ${ }^{\mathrm{e}}$ & & 15,1 & 26,1 & 32,5 & 32,6 \\
\hline - Alta tecnología ${ }^{\mathrm{f}}$ & & 8,0 & 10,8 & 15,0 & 21,8 \\
\hline Otros $^{\mathrm{g}}$ & & 2,8 & 3,5 & 3,4 & 3,8 \\
\hline III. 10 exportaciones principales según contribución ${ }^{\mathrm{h}}$ & i & 39,4 & 32,7 & 33,6 & 41,1 \\
\hline 781 Automóviles para pasajeros & + & 0,6 & 3,9 & 7,0 & 8,3 \\
\hline 333 Aceites de petróleo crudos, aceites crudos de min. bitumin. & - & 29,7 & 14,1 & 7,2 & 6,6 \\
\hline 764 Equipo de telecomunicaciones y partes y accesorios & + & 2,2 & 2,0 & 2,7 & 4,6 \\
\hline 762 Máq. para la elaboración automát. de datos y sus unidades & + & 0,1 & 1,1 & 1,8 & 3,8 \\
\hline 931 Operaciones y mercancías especiales no clasificadas & + & 1,9 & 2,7 & 2,7 & 3,3 \\
\hline 773 Material de distribución de electricidad & + & 1,6 & 2,9 & 3,5 & 3,3 \\
\hline 846 Ropa interior de punto o ganchillo & + & 0,6 & 1,1 & 2,3 & 3,0 \\
\hline 784 Partes y accesorios de vehículos automotores & + & 1,7 & 2,7 & 2,8 & 2,8 \\
\hline 761 Receptores de televisión & + & 0,3 & 1,6 & 2,6 & 2,7 \\
\hline $\begin{array}{l}769 \text { Partes y accesorios destinados a la fabricación de maquinarias de ofi- } \\
\text { cina (751) y de computación y elaboración automática de datos (752) }\end{array}$ & + & 0,7 & 0,6 & 1,0 & 2,7 \\
\hline
\end{tabular}

Fuente: Basados en el programa de cómputo TradeCAN 2002 Edition, CEPAL.

Grupos de bienes basados en la clasificación Uniforme de Comercio Internacional (CUCI Rev.2)

a. Contiene 45 productos básicos de sencillo procesamiento, incluye concentrados.

b. Contiene 65 elementos: 35 grupos agropecuarios/forestales y otros 30 (mayormente metales -excepto acero-, productos petroleros, cementos y vidrio, etc.)

c. Contiene 120 grupos que representan la suma de $\mathrm{d}+\mathrm{e}+\mathrm{f}$.

d. Contiene 44 elementos: 20 grupos del clúster de textil y prendas de vestir, más otros 24 (productos de papel, vidrio y acero, joyas).

e. Contiene 58 elementos: 5 grupos de la industria automotriz, 22 de la industria de procesamiento y 31 de la industria de ingeniería.

f. Contiene 18 elementos: 11 grupos del clúster de electrónica, más otros 7 productos (farmacéuticos, turbinas, aviones, instrumentos).

g. Contiene 9 grupos no clasificados (mayormente de la sección 9)

h. Grupos que corresponden $(*)$ a los 50 más dinámicos en las importaciones mundiales, 1985-2000.

i. Grupos donde se gana (+) o se pierde (-) participación de mercado en las importaciones mundiales, 1985-2000. 


\section{BIBLIOGRAFÍA BÁSICA}

CEPAL (Varios años), “A La inversión Extranjera en América Latina y el Caribe”. www.cepal.org.

CEPAL (2003), “Globalización y Desarrollo".

CEPAL (2003), "Panorama de la Inserción Internacional de América Latina y el Caribe, 2000/01".

Comisión Europea (2000), “El ABC del Derecho Comunitario”. Documentación Europea.

EUROSTAT: www.europa.eu.int/comm/eurostat/

Parlamento Europeo (1999), “Fichas Técnicas sobre la Unión Europea”. Luxemburgo.

Rodríguez Sánchez de Alva, A. (1999), "Desarrollo y Cooperación en una Economía Globalizada”. Universidad de Sevilla y Fundación El Monte. 